\title{
Experimental study on the martensitic transformation in AISI 304 steel sheets subjected to tension under wide ranges of strain rate at room temperature
}

\author{
J.A. Rodríguez-Martínez ${ }^{\mathrm{a}, *}$, R. Pesci $^{\mathrm{b}}$, A. Rusinek ${ }^{\mathrm{c}}$ \\ a Department of Continuum Mechanics and Structural Analysis, University Carlos III of Madrid, Avda. de la Universidad 30, 28911 Leganés, Madrid, Spain \\ ${ }^{\mathrm{b}}$ ENSAM-Arts et Métiers ParisTech, Laboratory of Physics and Mechanics of Materials (LPMM), FRE CNRS 3236, 4 Rue Augustin Fresnel, 57078 Metz Cedex 3, France \\ c National Engineering School of Metz (ENIM), Laboratory of Mechanics, Biomechanics, Polymers and Structures (LaBPS), 1 route d'Ars Laquenexy, 57078 Metz Cedex 3, France
}

\section{Keywords:}

Martensitic transformation

AISI 304 steel

X-rays diffraction

Infrared thermography

\begin{abstract}
A B S T R A C T
In this work, the martensitic transformation occurring in AISI 304 steel sheets subjected to tension at room temperature has been experimentally studied. Tensile tests performed on AISI 304 specimens are split into two different types; in situ tensile tests and macroscopic tensile tests. The former are conducted mounting the sample in a tensile micromachine originally developed in ENSAM/Metz within the range of strain rates $10^{-5} \mathrm{~s}^{-1} \leq \dot{\varepsilon} \leq 10^{-3} \mathrm{~s}^{-1}$. The latter are performed under static and dynamic conditions of deformation within the range of strain rates $10^{-3} \mathrm{~s}^{-1} \leq \dot{\varepsilon} \leq 10^{2} \mathrm{~s}^{-1}$. Using X-rays diffraction technique, in situ tensile tests have allowed measuring the stress of the phases during loading by placing the tensile micromachine under the range of a PROTO goniometer. Additionally, the martensitic transformation has been recorded via mounting the tensile micromachine into a scanning electron microscope. The volume fraction of martensite has been measured in the post mortem specimens, $V_{\alpha^{\prime}} \approx 70 \%$. Moreover, the static macroscopic tensile tests, $10^{-3} \mathrm{~s}^{-1} \leq \dot{\varepsilon} \leq 10^{-1} \mathrm{~s}^{-1}$, have been recorded using a high speed infrared camera. It has been proven that martensitic transformation takes place in AISI 304 steel for a temperature increase over $\Delta T>140 \mathrm{~K}$. The macroscopic dynamic tensile tests are performed within the range of strain rates, $1 \mathrm{~s}^{-1} \leq$ $\dot{\varepsilon} \leq 100 \mathrm{~s}^{-1}$. A considerable amount of martensite has been detected in the post mortem samples, $V_{\alpha^{\prime}} \approx 35 \%$. This proves that plastic deformation is the dominant mechanism responsible for the transformation phenomenon in this steel. The free energy supplied by straining the sample relegates to a secondary role the rise in temperature taking place during the course of plastic deformation.
\end{abstract}

\section{Introduction}

Good formability and toughness in addition to high strength are mechanical properties demanded by industry for steels applied to the construction of mechanical elements with elevated structural responsibility. Metastable austenitic stainless steels are one type of steels that offer such convenient characteristics. Such improved mechanical properties are induced by the microstructural transformation from austenite to martensite taking place in this sort of steels under determined loading conditions.

As described by Angel [1], the controlling factor for the kinetics of the transformation is the supply of free energy. In other words, the transformation requires a free-energy variation of the system large enough to enable the reaction to mount the activation barrier between austenite and martensite [1-3]. This can be triggered either by quenching or by loading the sample [4].

\footnotetext{
* Corresponding author. Tel.: +34 91624 8809; fax: +34 916249430

E-mail address: jarmarti@ing.uc3m.es (J.A. Rodríguez-Martínez).
}

In the case of the metastable austenitic stainless steel grades, martensitic transformation may occur at room temperature by material straining. This process, commonly called Strain-Induced Martensitic Transformation (SIMT), enhances the work hardenability of the steel and delays plastic localization improving the formability of the material [4,5]. Additionally, the martensitic transformation causes the Transformation Induced Plasticity (TRIP) process. There are two mechanisms behind the TRIP effect [5]:

- The "Magee effect" [6] related to crystallographic orientation with transformation of preferred variants. This process relaxes the tensile hydrostatic stress which is responsible for damage or micro cracking.

- The "Greenwood-Johnson effect" [7] related to the displacive character of the austenite-martensite transformation [8]. It corresponds to the plastic strain induced in the parent phase because of the volume difference between two coexisting phases. This effect contributes to enhance material strain hardening.

Taking into account the number of related publications [1,9-15], the AISI 304 may be considered as the reference metastable 
Table 1

Chemical composition of AISI 304 (weight \%, Fe balance).

\begin{tabular}{llllllll}
\hline $\mathrm{C}$ & $\mathrm{Mn}$ & $\mathrm{Cr}$ & $\mathrm{Ni}$ & $\mathrm{Mo}$ & $\mathrm{Cu}$ & $\mathrm{Si}$ & $\mathrm{Nb}$ \\
\hline 0.06 & 1.54 & 18 & 8 & 0.30 & 0.37 & 0.48 & 0.027 \\
\hline
\end{tabular}

austenitic stainless steel for studying the SIMT process. This work agrees with those previously cited and presents a detailed experimental survey on the martensitic transformation occurring in AISI 304 steel sheets subjected to tension at room temperature. New findings concerning the loading conditions under which the SIMT process occurs in the AISI 304 are presented. Advanced measuring techniques like X-Rays Diffraction (XRD) technique and Thermal Imaging (TI) have been applied for that task.

\section{Microstructure and chemical composition of the AISI 304 steel}

The material studied in this work is a rolled AISI 304 steel which is the most versatile and most widely used stainless steel. This material enjoys a wide range of applications because of good corrosion resistance, elevated strength and ductility, as well as excellent weldability and formability.

The AISI 304 belongs to the type called high-alloy TRIP steels. This sort of steels contain large amount of alloying elements such as $\mathrm{Cr}$ and $\mathrm{Ni}$, improving pitting and corrosion resistance. The chemical composition of the material is given in Table 1.

In the undeformed state, the AISI 304 is constituted of $100 \%$ of austenite. The average grain size has been determined from Scanning Electron Microscope (SEM) and Electron Back-Scattered Diffraction (EBSD) observations, $D \approx 12 \mu \mathrm{m}$. The martensite start temperature of this material $M_{\mathrm{S}} \approx 65 \mathrm{~K}$ has been measured using a dilatometer (cooling speed of $20^{\circ} \mathrm{C} / \mathrm{s}$ ). Moreover, the X-ray Diffraction (XRD) technique (see Section 3) enabled to point out that no texture was present in austenite in the undeformed state. The intensity factor recorded was less than 2, Fig. 1.

In the next section of this paper, XRD and TI measurement techniques are introduced. Both have been used to determine the loading conditions under which martensite is formed in the AISI 304 steel at room temperature.
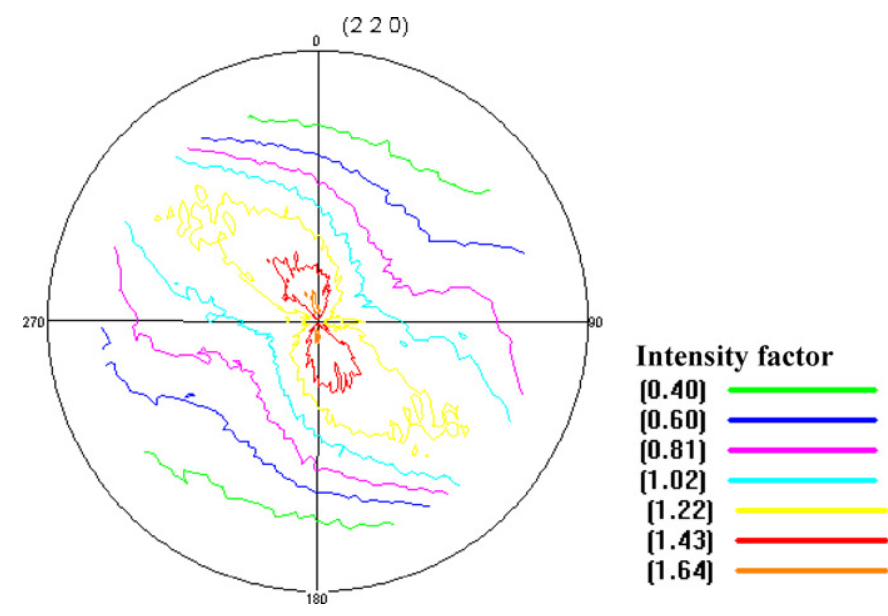

Fig. 1. $\{220\}$ pole figure of austenite in the initial state at room temperature.

\section{Advanced measuring techniques applied to study the martensitic transformation}

\subsection{X-rays diffraction technique}

XRD has been used since it is a very efficient non-destructive technique that enables to determine accurately the volume fraction of each phase as well as the average stress state in the coexisting phases [16].

Thus, XRD has been used in order to:

- Measure the stress of the phases both during loading (in situ tensile tests) and in the post-mortem specimens.

- Measure the volume fraction of the phases in the post-mortem specimens.

\subsubsection{Measurement of the stress in the phases}

The level of stress in each phase of the steel is determined on the surface of the specimens using a portable PROTO goniometer [16]. It enables to analyze elaborately shaped parts since the sample stays fixed during the whole analysis (the beam is moving around the specimen). The longitudinal direction of the active part of the sample is aligned with the direction of the movement of the PROTO goniometer beam.

For stress determination, the classical $\sin ^{2} \psi$ method has been used considering the lattice plane spacing $d_{h k l}$ of a $\{h k l\}$ plane family as an internal strain gauge $[17,18]$. The FCC phase (austenite) is analyzed by using manganese radiation $(\lambda=2.102 \AA)$; in order to obtain optimum results, the analysis of the $\{311\}$ planes corresponding to an angle $2 \theta=151.0^{\circ}$ is conducted (best accuracy). For the $\mathrm{BCC}$ phase (martensite) chromium radiation is used $(\lambda=2.2897 \AA)$ and the $\{211\}$ planes are analyzed $\left(2 \theta=156.1^{\circ}\right)$.

\subsubsection{Measurement of the volume fraction of the phases}

The volume fraction of each phase has been calculated using a SEIFERT XRD 3003 PTS goniometer taking into account the intensity of the diffraction peaks of martensite and austenite.

In the case of AISI 304, a material containing two phases, the volume fraction of martensite is obtained by Eq. (1).

$V_{\alpha^{\prime}}=\frac{1}{\left[1+\left(I_{\gamma} / I_{\alpha^{\prime}}\right) \cdot\left(\left(R_{\alpha^{\prime}} / R_{\gamma}\right)\right)\right]}$

where $I_{\alpha^{\prime}}$ and $I_{\gamma}$ are the intensity of the diffraction peaks for martensite and austenite, respectively, $R_{\alpha^{\prime}}$ and $R_{\gamma}$ are coefficients depending on the absorption factor, the Lorentz polarization factor, the multiplicity factor of the analyzed plane families, the volume of the crystal lattices and others [17]. Furthermore, $V_{\alpha^{\prime}}+V_{\gamma}=1$. Both phases (austenite and martensite) have been analyzed by using an iron anticathode $(\lambda=1.936 \AA)$.

\subsection{Infrared thermography}

The infrared camera used for measuring temperature contours features variable "snap shot" integration from $10 \mu \mathrm{s}$ to $10 \mathrm{~ms}$ and frame rates up to 200 FPS (frames per second) in full frame mode and 6000 FPS in sub-windowing mode. The minimum temperature variation registered by the camera is $\Delta T_{\min }=18 \mathrm{mK}$. The integration time is within the range $1 \mathrm{~ms} \leq t_{\text {int }} \leq 20 \mathrm{~ms}$. Such features allow having high definition and elevated frame-rates [19].

In order to get the maximum emissivity from the sample, the steel specimens were covered with soot the emissivity of which was estimated $\eta=0.95$ (before loading, the temperature registered by the camera on the soot-coated target-surface must fit the room temperature) [19-21]. 

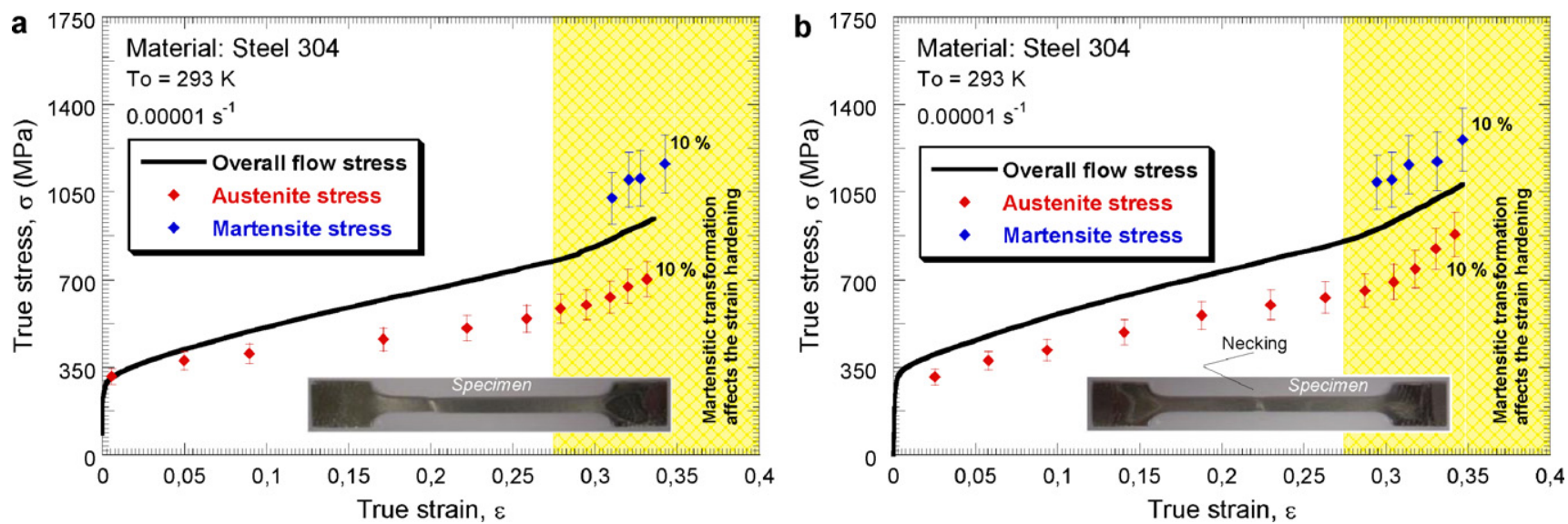

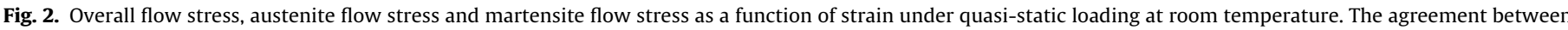
both graphs show the repeatability of the tests.

\section{Experimental methodology}

Tensile tests under a wide range of strain rates have been performed, $10^{-5} \mathrm{~s}^{-1} \leq \dot{\varepsilon} \leq 10^{2} \mathrm{~s}^{-1}$. These tests are split into two different types, in situ tensile tests and macroscopic tensile tests. The volume fraction of martensite has been determined in all the samples after testing.

\subsection{In situ tensile tests}

The sample is mounted in a tensile micromachine originally developed in ENSAM/Metz [22]. The active part of the specimens is $30 \mathrm{~mm}$ long, $4 \mathrm{~mm}$ wide and $1 \mathrm{~mm}$ thick [23]. This arrangement enables to perform low rate tests within the range $10^{-5} \mathrm{~s}^{-1} \leq \dot{\varepsilon} \leq$ $10^{-3} \mathrm{~s}^{-1}$. Application of this experimental setup allows for:

- Determination of the stress of the phases during straining on the surface of the specimen by placing the tensile micromachine under the range of the PROTO goniometer.

- Direct observation of the martensitic transformation during loading by mounting the tensile micromachine into a SEM.

\subsection{Macroscopic tensile tests}

Macroscopic tensile tests are performed within the range of strain rates $10^{-3} \mathrm{~s}^{-1} \leq \dot{\varepsilon} \leq 10^{2} \mathrm{~s}^{-1}$. The active part of the specimens is $20 \mathrm{~mm}$ long, $8 \mathrm{~mm}$ width and $1 \mathrm{~mm}$ thick $[23,24]$. They are split into two different types:

- Low strain rate tests $10^{-3} \mathrm{~s}^{-1} \leq \dot{\varepsilon} \leq 10^{2} \mathrm{~s}^{-1}$ : they are performed in a universal testing machine. These tests are filmed using a high speed infrared camera.

- High strain rate tests $1 \mathrm{~s}^{-1} \leq \dot{\varepsilon} \leq 10^{2} \mathrm{~s}^{-1}$ : they are performed in a fast hydraulic tensile machine.

The experimental results obtained are presented and discussed in the following part.

\section{Characterization of the martensitic transformation in AISI 304 steel sheets subjected to tension}

The first step is to analyze the results obtained from the in situ tensile tests.

\subsection{In situ tensile tests}

At room temperature and low loading rate, the AISI 304 shows an initial yield stress close to $\left.\sigma\right|_{\varepsilon \mathrm{p}=0} \approx 300 \mathrm{MPa}$, Fig. 2. This material possesses remarkable strain hardening which enhances ductility, $\varepsilon_{\text {failure }} \approx 0.35$.

As previously mentioned, the tensile micromachine is placed under a PROTO goniometer, the stress in each phase of the steel has been determined during straining. The repeatability of the
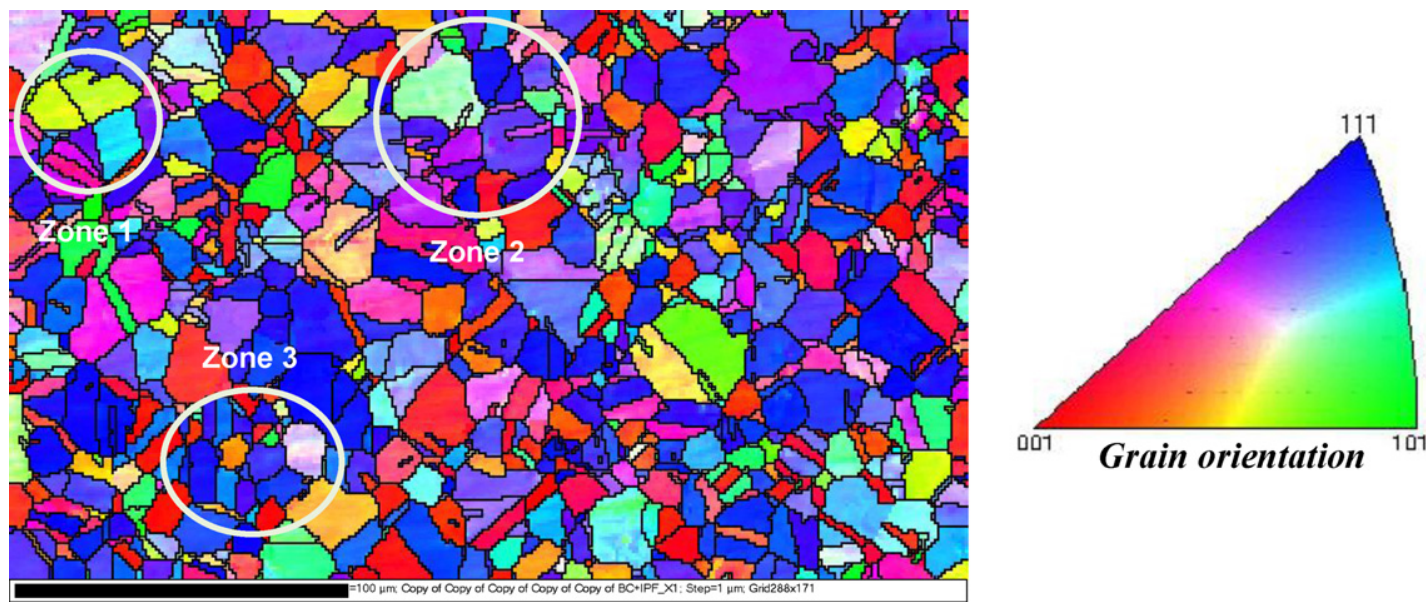

Fig. 3. EBSD mapping of one specimen before a tensile test. 


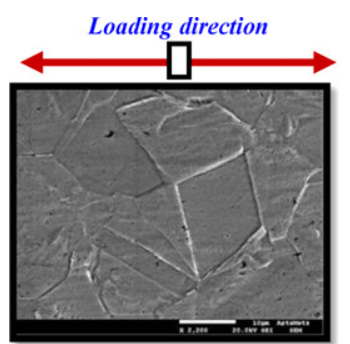

Initial state

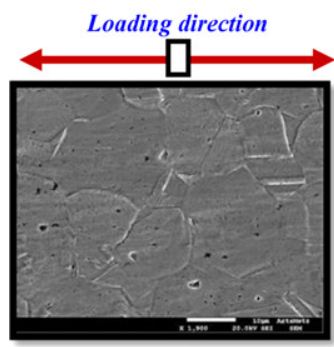

Initial state

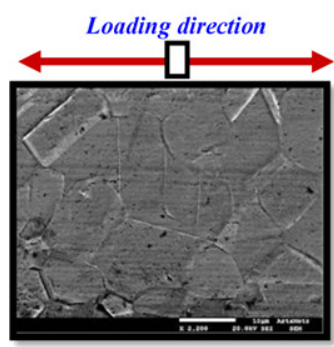

Initial state

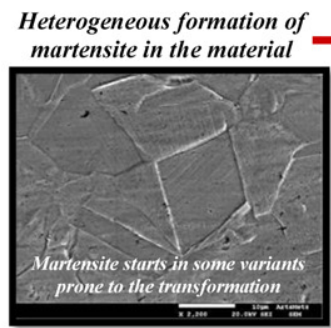

$\varepsilon_{p}=0.048$

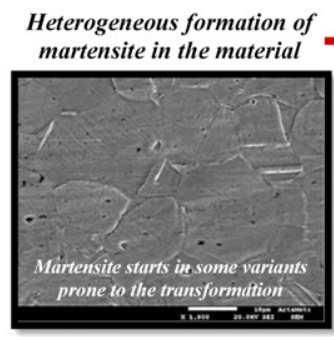

$\varepsilon_{p}=0.048$

Heterogeneous formation of martensite in the material

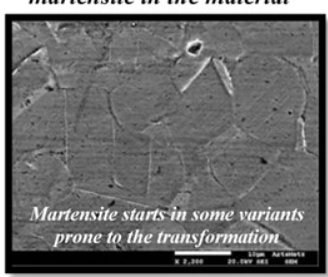

$\varepsilon_{p}=0.048$
Zone 1

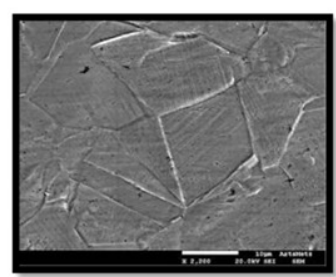

$\varepsilon_{p}=0.095$

Zone 2

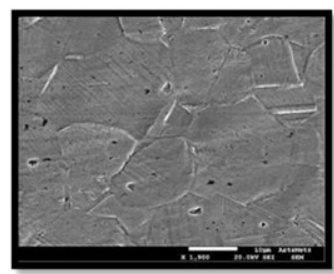

$\varepsilon_{p}=0.095$

Zone 3

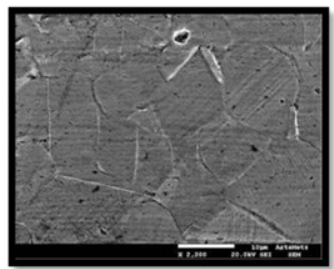

$\varepsilon_{p}=0.095$

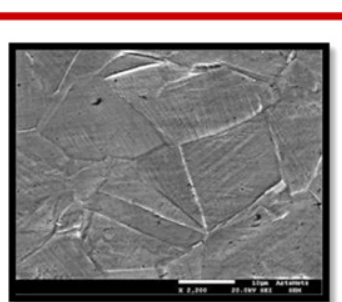

$\varepsilon_{p}=0.182$

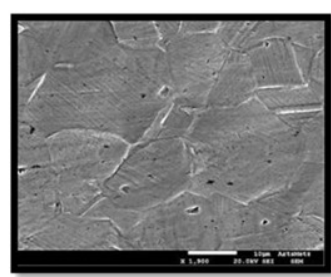

$\varepsilon_{p}=0.182$

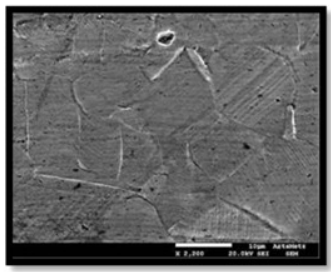

$\varepsilon_{p}=0.182$
Homogeneous formation of martensite in the material

Homogeneous formation of martensite in the material

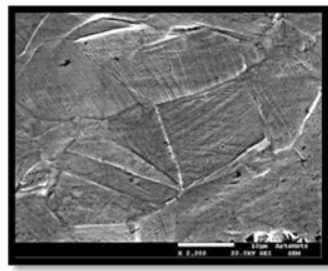

$\varepsilon_{p}=0.262$

Homogeneous formation of martensite in the material
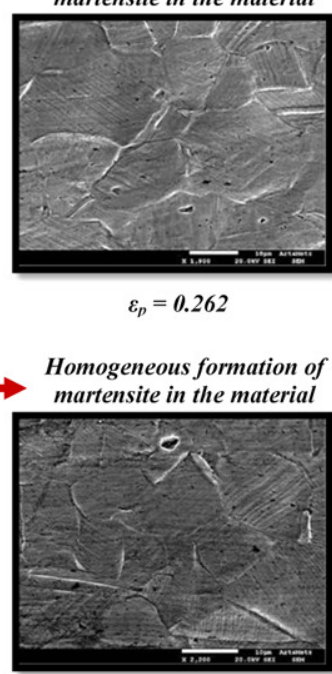

$\varepsilon_{p}=0.262$

Fig. 4. Evolution of the martensitic transformation in three different zones of the tested sample during loading at room temperature.

measurements must be highlighted. For all the tests conducted, austenite acts as the soft phase of the material, Fig. 2. Due to the gap existing between austenite flow stress and overall flow stress, it is concluded that martensitic transformation has started at the very beginning of the loading process. However, in the case of $\varepsilon^{\mathrm{p}}<0.27$ it was not possible to measure the stress in martensite. For such a range of strains, $\varepsilon^{\mathrm{p}}<0.27$, the volume fraction of martensite seems to be quite reduced $V_{\alpha^{\prime}}<5 \%$. This makes very difficult a proper determination of the stress in martensite using XRD. The resulting diffraction peaks are so little intense that no reliable analysis can be done with a good precision. To overcome this problem, ring diffraction with synchrotron emission may be applied since it displays higher X-ray flux and increased diffracting volume [25].

Thus, strain hardening of the material stays approximately constant until $\varepsilon^{\mathrm{p}} \approx 0.27$, then the flow stress sharply increases (change in slope visible in Fig. 2). It seems that, in order to induce the visible extra strain hardening reported in Fig. 2, a large volume of martensite is required, $V_{\alpha^{\prime}}>10 \%$.

In order to conduct a direct observation of the martensitic transformation, in situ tensile tests are performed placing the tensile micromachine into a SEM. For that task an EBSD mapping is conducted on one specimen in the undeformed state, Fig. 3. Three sample zones have been selected to perform visual tracking of the process of martensitic transformation during loading, Fig. 3.

This test demonstrates that, actually, the martensitic transformation starts at the beginning of loading, Fig. 4. However, for low values of macroscopic deformation $\varepsilon^{\mathrm{p}}=0.048$ and $\varepsilon^{\mathrm{p}}=0.095$, relevant differences in the process of martensitic transformation are detected for different grains [26], Fig. 4. The amount of martensite formed in each grain can strongly vary with the appearance of none, one or several variants. Thus, for low and moderate strains the distribution of martensite detected in the material is quite heterogeneous and it is focused in selected grains especially prone to the transformation, Fig. 4.

As the macroscopic strain applied to the specimen increases $\varepsilon^{\mathrm{p}} \approx 0.182$, different variants of martensite are formed, practically, in most of grains. For larger macroscopic deformation $\varepsilon^{\mathrm{p}} \approx 0.26$, we can see that the amount of martensite formed in the material during the loading process is quite important and, now, homogeneously distributed Fig. 4. As previously mentioned, for this value of straining, the macroscopic flow stress of the material started to be clearly affected by the martensite formation.

For larger values of plastic deformation $\varepsilon^{\mathrm{p}}>0.26$, the microstructure of the material became quite difficult to observe, the grain boundaries cannot be determined. In that range of straining $\varepsilon^{\mathrm{p}}>0.26$, grains distortion makes impossible to derive any relevant conclusion concerning the martensitic transformation using SEM observations.

Additionally, it has been checked that no texture is present in martensite after testing. The intensity factor recorded was less than 2, Fig. 5. It proves that beyond a certain value of deformation, martensite is homogeneously formed in the material, without any preferential direction.

Next, the volume fraction of martensite in the specimens tested is determined, Fig. 6 . The amount of martensite varies between $V_{\alpha^{\prime}} \approx 55 \%$ in both ends of the active part of the specimen (lowest deformation) and $V_{\alpha^{\prime}} \approx 70 \%$ in the necking zone (greatest deformation), Fig. 6. It is clear that the volume fraction of martensite detected in the active part of the sample depends on the level of straining. The greatest straining leads to the greatest volume fraction 


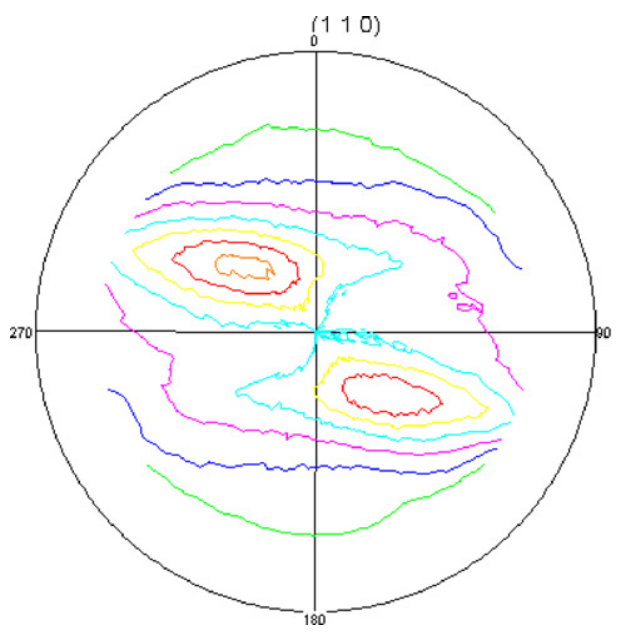

Intensity factor

[0.19]

[0.50]

[0.81]

[1.13]

$[1.44]$

[1.75]

[2.07]

Fig. 5. $\{110\}$ pole figure of martensite after failure at room temperature.

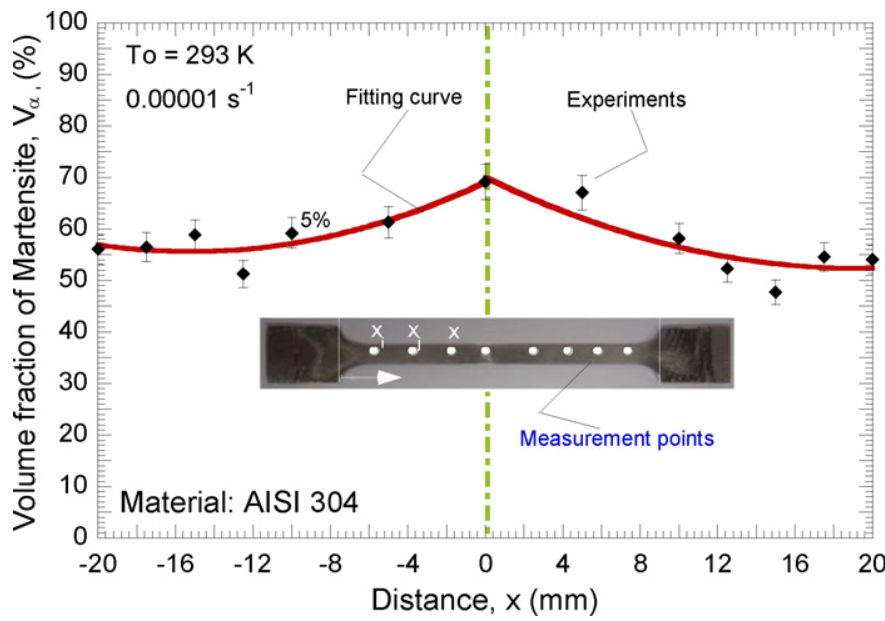

Fig. 6. Volume fraction of martensite after testing along the active part of the specimen.

of martensite. Moreover, it has to be noted that, under the same loading conditions, such an amount of martensite is larger than that determined in the literature for the AISI 304 through magnetic techniques, $V_{\alpha^{\prime}} \approx 40 \%[10-12]$.

Next, the results obtained from the macroscopic tensile tests are discussed.

a

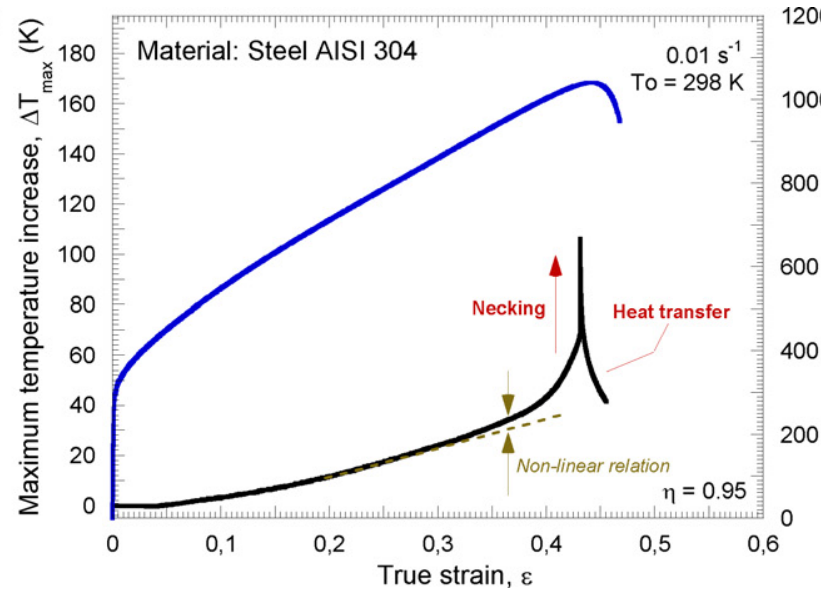

\subsection{Macroscopic tensile tests}

As previously mentioned, the macroscopic low rate tests have been recorded using a high speed infrared camera. In several works $[27,28]$ has been reported that infrared thermography allows for relevant analyses of local phenomena, like martensitic transformation, which may occur in determined metallic materials under loading. Thus, in the following graphs, Fig. 7., the maximum increase of temperature (temperature in the necking) during loading in the case of $\dot{\varepsilon}=0.01 \mathrm{~s}^{-1}$ is reported. The material temperature is continuously increasing with stress and strain. The non-linear relation between temperature increase and plastic deformation (during homogenous deformation of the sample) is due to both the dependence of the inelastic heat fraction on plastic strain (interesting considerations concerning the potential dependence of Taylor-Quinney coefficient on plastic deformation are reported in $[21,29]$ ) and the martensitic transformation (which is an exothermic process [30]). Then instability takes place, and a sudden increase of temperature is observed, Figs. 7 and 8. At that moment, high strain rate level is reached in the necking, the deformation process seems to become locally adiabatic. The heat generated in the instability is hardly diffused to the rest of the sample, Fig. 8. Maximum temperature recorded during the test is close to $\Delta T_{\max } \approx 110 \mathrm{~K}$.

Tests at higher strain rates have been performed. At $\dot{\varepsilon}=0.1 \mathrm{~s}^{-1}$ the maximum temperature during the test reaches $\Delta T_{\max } \approx 140 \mathrm{~K}$, Fig. 9.

An heterogeneous distribution of temperature is reached as early as the first stages of the deformation process, Fig. 10. Temperature increase is soon concentrated in the central part of the specimen, Fig. 10. There, in the necking, the material behaves under adiabatic conditions of deformation. Once instability takes place, the evolution of temperature (in the necking) with global deformation sharply raises, almost following a vertical asymptote, Fig. 9. Therefore, strong gradients of strain and strain rate are expected in the necking zone.

Then, the martensite stress distribution and the volume fraction of martensite along the active part of the tested samples are obtained, Fig. 11. It is of great relevance to highlight that in AISI 304 martensitic transformation takes place for a temperature increase over $\Delta T>140 \mathrm{~K}$. In the works by Tomita and co-workers [10-12] much lower values of temperature $\approx 323 \mathrm{~K}$ were considered to define $M_{\mathrm{d}}\left(M_{d}\right.$ represents the temperature at which no martensitic transformation takes place, no matter the plastic deformation of the austenite phase).

The amount of martensite varies between $V_{\alpha^{\prime}} \approx 25 \%$ in both ends of the active part of the specimen (lowest deformation) and $V_{\alpha^{\prime}} \approx 50 \%$

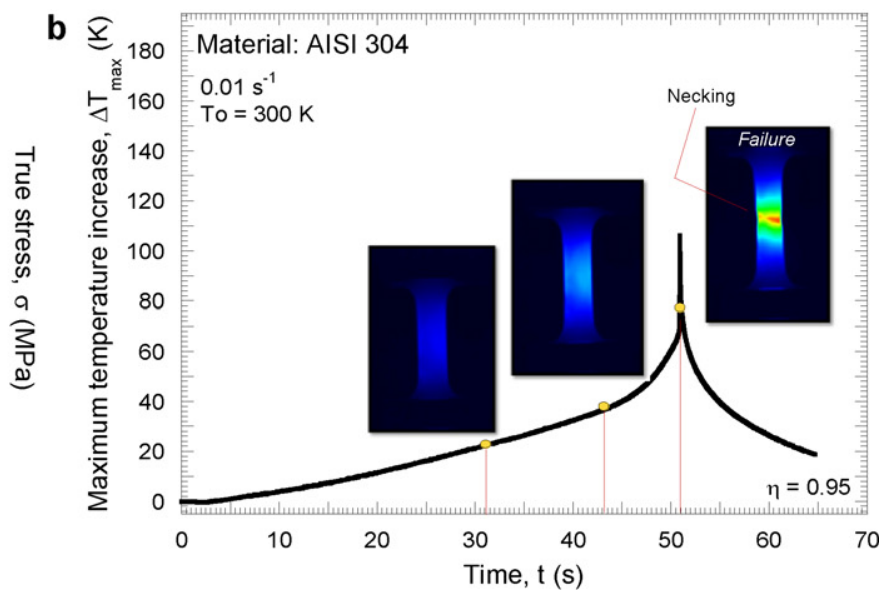

Fig. 7. (a) Maximum temperature increase versus plastic strain and flow stress evolution versus plastic strain. (b) Maximum temperature increase versus time. 


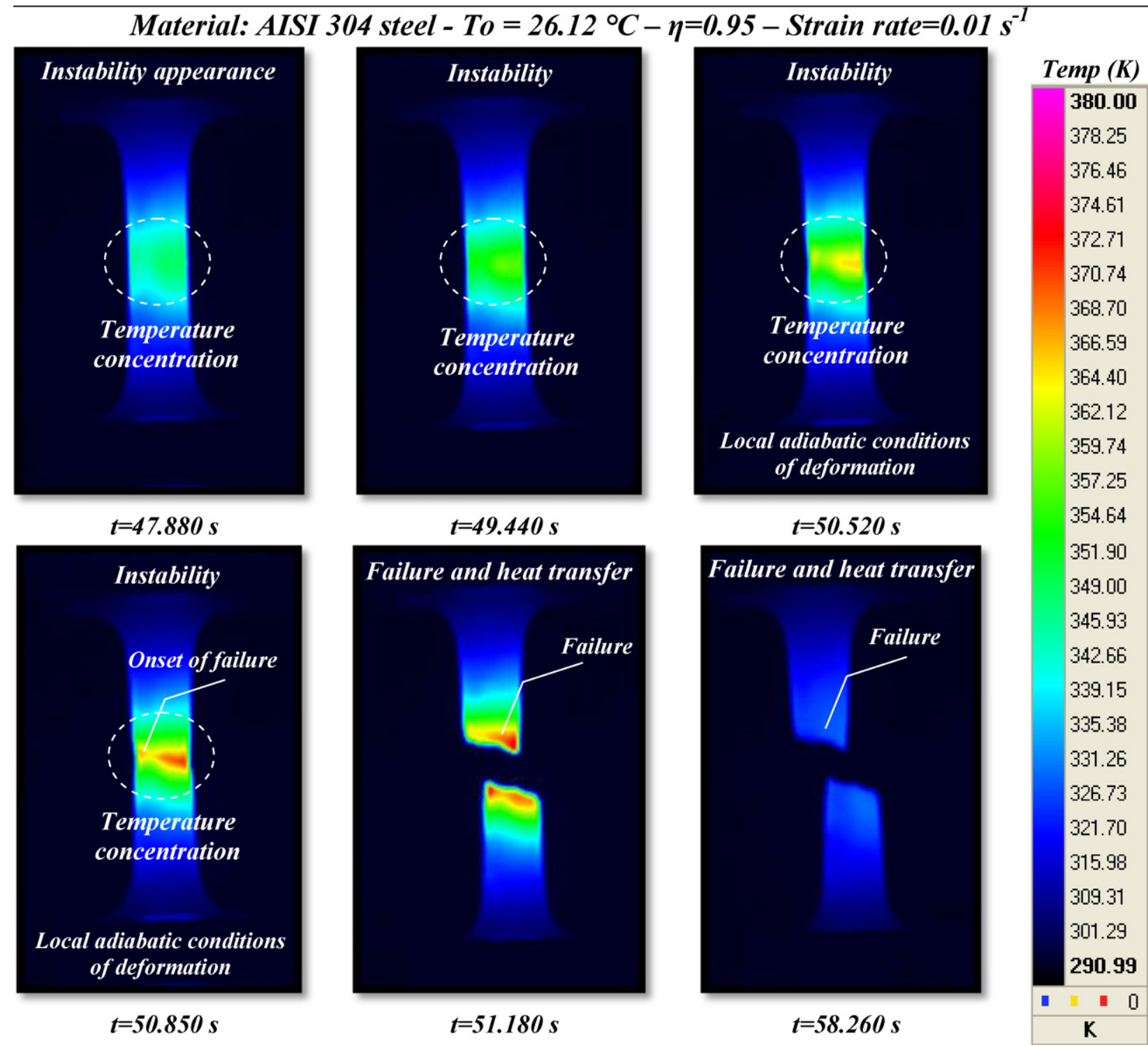

Fig. 8. Temperature contours during loading for $0.01 \mathrm{~s}^{-1}$ at room temperature. Picture resolution $320 \times 256$ pixels (pixels length $30 \mu \mathrm{m}$ ).
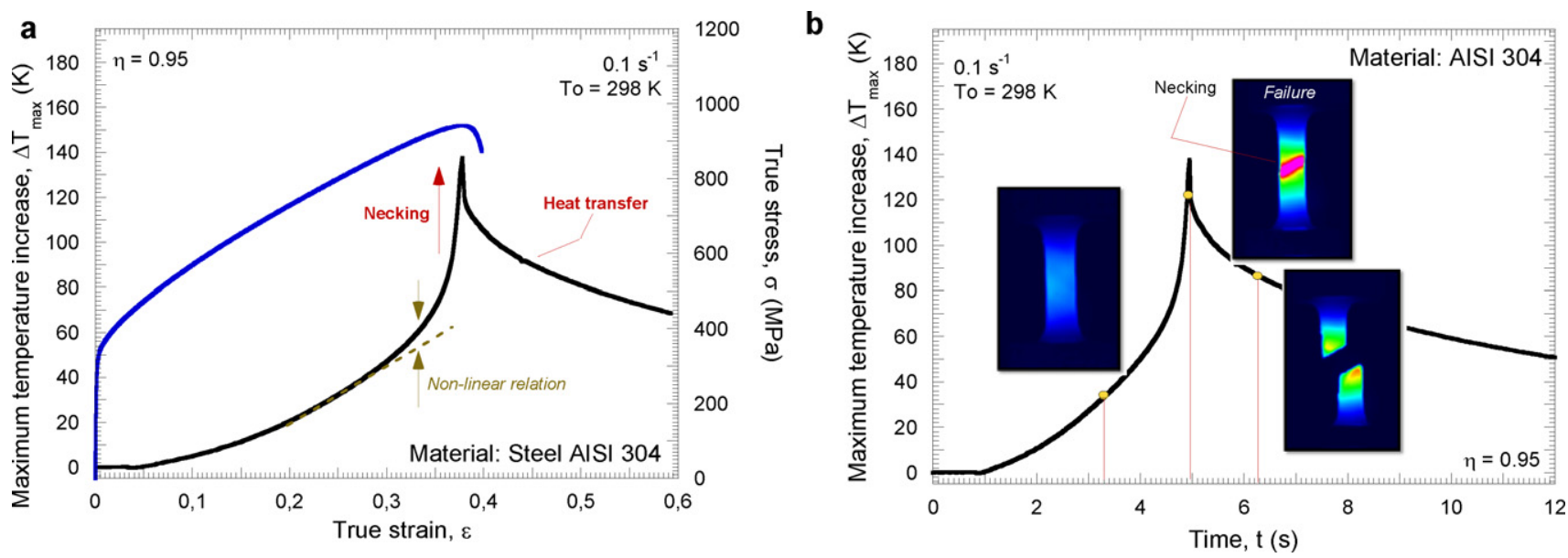

Fig. 9. (a) Maximum temperature increase versus plastic strain and flow stress evolution versus plastic strain. (b) Maximum temperature increase versus time. 
Material: AISI 304 steel - To $=26.12^{\circ} \mathrm{C}-\eta=0.95-$ Strain rate $=0.1 \mathrm{~s}^{-1}$
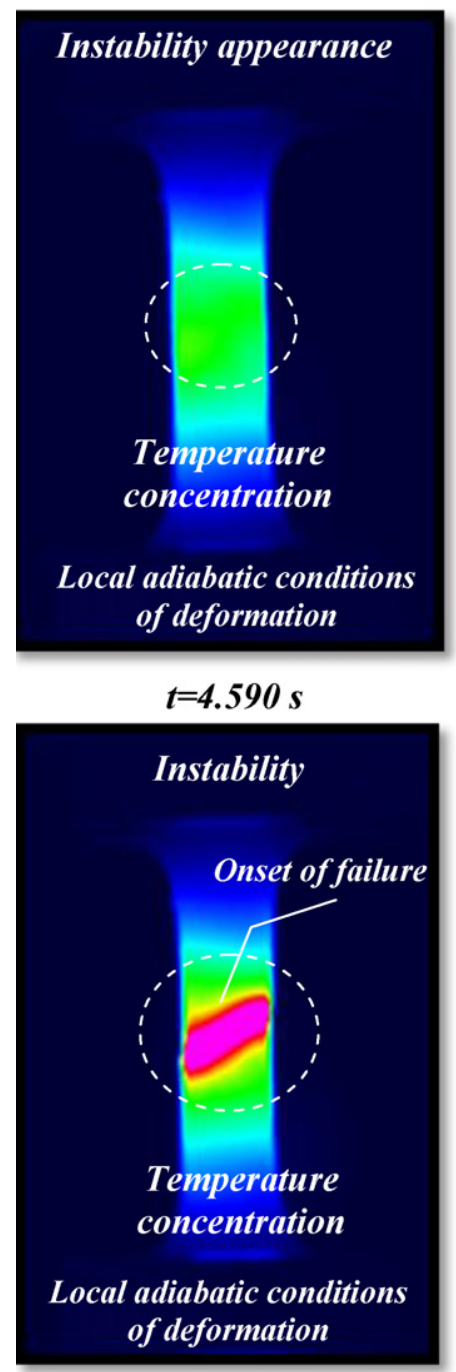

$t=4.920 \mathrm{~s}$
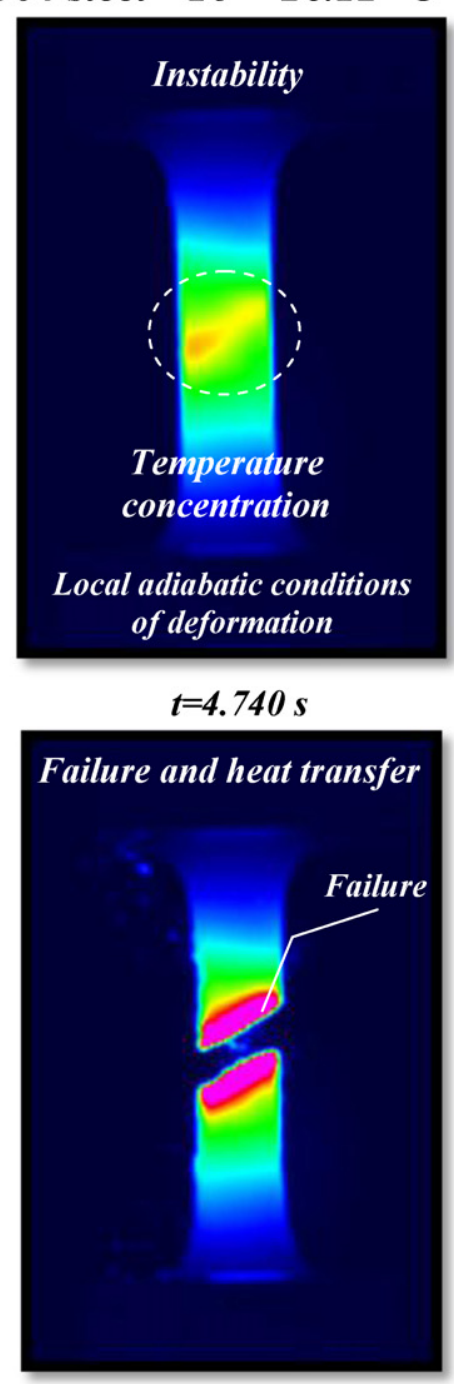

$t=4.950 \mathrm{~s}$
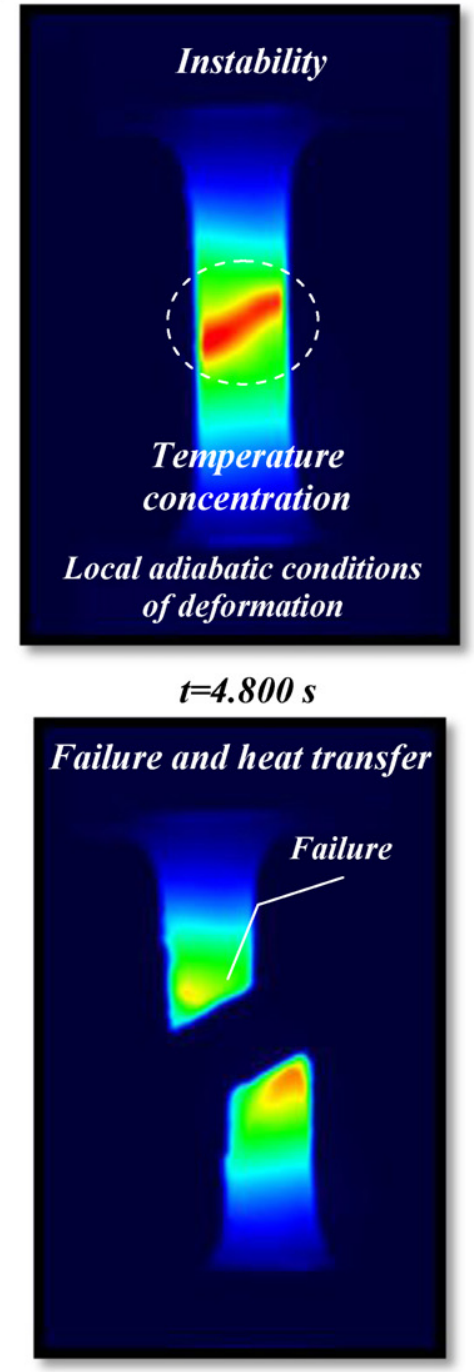

$t=6.270 \mathrm{~s}$

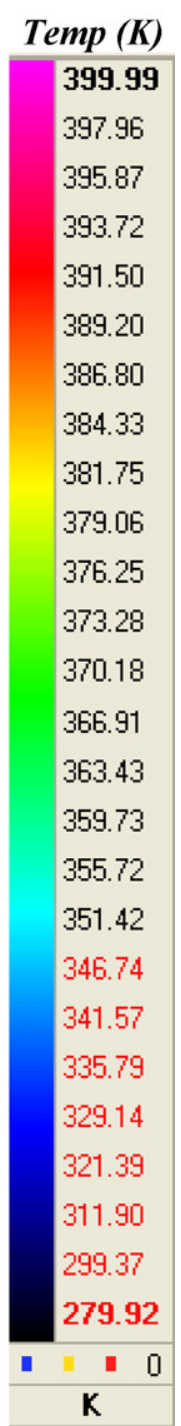

Fig. 10. Temperature contours during loading for $0.1 \mathrm{~s}^{-1}$ at room temperature. Picture resolution $320 \times 256$ pixels (pixels length $30 \mu \mathrm{m}$ ).

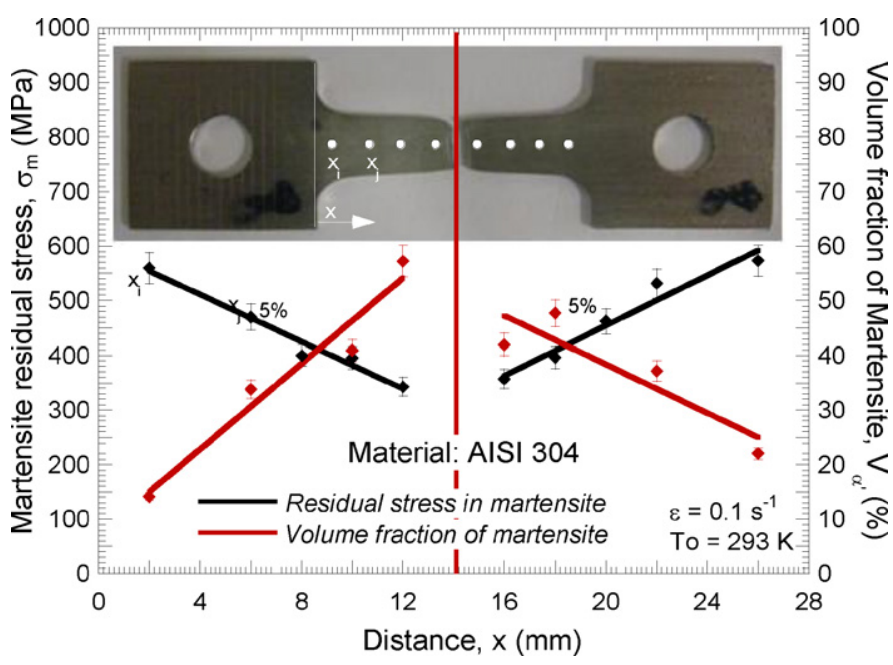

Fig. 11. Residual stress in martensite and volume fraction of martensite in tensile specimens tested for $0.1 \mathrm{~s}^{-1}$ at room temperature.

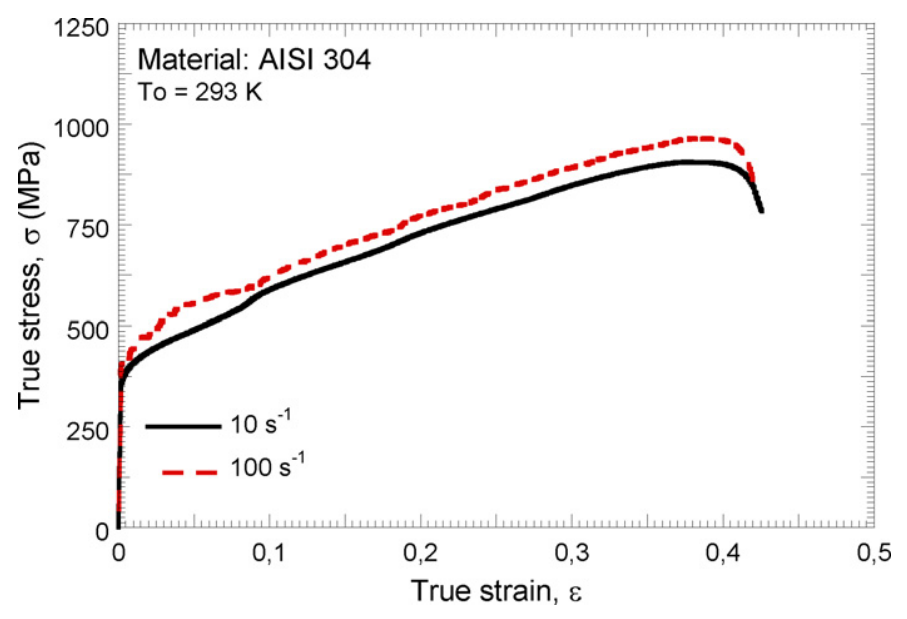

Fig. 12. Flow stress evolution as a function of strain for different strain rate levels at room temperature. 

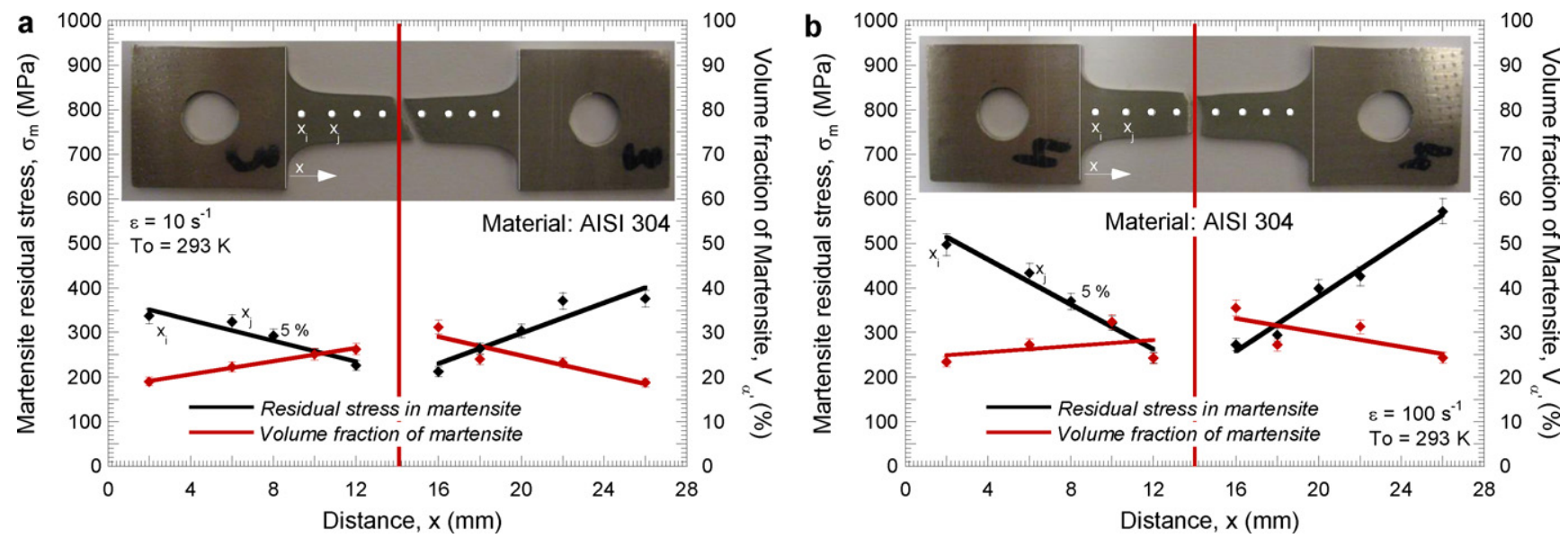

Fig. 13. Residual stress in martensite and volume fraction of martensite in tensile specimens tested at different strain rates at room temperature. (a) $10 \mathrm{~s}^{-1}$, (b) $100 \mathrm{~s}^{-1}$.

in the necking zone (greatest deformation). Then, residual stress in martensite follows an opposite trend, Eq. (2).

$0=\sigma_{\alpha^{\prime}} \cdot V_{\alpha^{\prime}}+\sigma_{\gamma} \cdot V_{\gamma}$

Since the greatest volume fraction of martensite is located in the necking it seems that plastic deformation is the dominant mechanism which resides behind the transformation phenomenon in this material. The free energy supplied by the material straining relegates to a secondary role the increase of temperature (inhibitor of martensitic transformation) due to conversion of plastic work into heat and due to martensitic transformation (which as previously mentioned is an exothermic process [30]).

Next, let us examine if martensite is formed in the AISI 304 under high loading rates. In Fig. 12 stress-strain curves obtained from the macroscopic high rate tests are shown.

A relevant amount of martensite has been found in the dynamically tested samples. The volume fraction of martensite varies between $V_{\alpha^{\prime}} \approx 20 \%$ in both ends of the active part of the specimen (lowest deformation, lowest temperature) and $V_{\alpha^{\prime}} \approx 35 \%$ in the necking zone (greatest deformation, greatest temperature increase), Fig. 13. Such a trend confirms the expectations raised from the macroscopic low rate tests: straining is the main factor controlling the martensitic transformation. This leads to the formation of martensite even under a sharp increase of temperature.

Thus, it seems that martensitic transformation is responsible for the elevated work hardening and ductility that the AISI 304 (also) shows under high loading rates, Figs. 12 and 13.

Martensitic transformation occurring in the AISI 304 under dynamic conditions of deformation makes this material suitable for engineering applications where ductility and toughness are required. Thanks to the martensitic transformation, this material displays improved capability for absorbing energy under impulsive loads [31]. This finding is of main interest for certain engineering applications involving high structural responsibility in which the AISI 304 is frequently used, such as pipelines or heat exchangers that may be potentially subjected to explosions or attacks.

\section{Conclusions and remarks}

In this work the martensitic transformation occurring in AISI 304 steel sheets subjected to tension at room temperature has been experimentally studied. The research is of main interest for different engineering fields such as nuclear industry, automotive industry or marine applications where this material is extensively used. Remarks and conclusions derived from the analysis can be summarized as follows:
- In situ tensile tests

- The stress of the phases during loading has been determined on the surface of the samples by placing the tensile micromachine under the range of the PROTO goniometer. The range of strain rates covered during these tests is $10^{-5} \mathrm{~s}^{-1} \leq \dot{\varepsilon} \leq 10^{-3} \mathrm{~s}^{-1}$. It has been determined that martensitic transformation already occurs in the AISI 304 for low values of plastic deformation. However, the amount of martensite formed remains quite reduced, $V_{\alpha^{\prime}}<5 \%$ until a certain value of plastic strain is reached $\varepsilon^{\mathrm{p}} \approx 0.27$. Then, the martensite volume fraction rapidly increases, leading to a sudden rise of the material strain hardening.

- The martensitic transformation has been recorded by placing the tensile micromachine into a SEM. This arrangement allowed for the observation that for low and moderate values of plastic deformation $\varepsilon^{\mathrm{p}}<0.15$, the formation of martensite is quite inhomogeneous and is focused in selected grains particularly prone to the transformation. With increasing sample straining, that trend is corrected and different variants of martensite are formed, practically, in each grain. In the necking, where maximum material straining occurs, the volume fraction of martensite measured in the tested samples is $V_{\alpha^{\prime}} \approx 70 \%$.

- Macroscopic tensile tests

- The macroscopic low rate tests, $10^{-3} \mathrm{~s}^{-1} \leq \dot{\varepsilon} \leq 10^{-1} \mathrm{~s}^{-1}$, have been recorded using a high speed infrared camera. It has been proven that martensitic transformation takes place in AISI 304 for temperature increase over $\Delta T>140 \mathrm{~K}$. In the necking, the volume fraction of martensite measured is $V_{\alpha^{\prime}} \approx 50 \%$.

The dynamic tensile tests have been performed within the range of strain rates, $1 \mathrm{~s}^{-1} \leq \dot{\varepsilon} \leq 100^{-1} \mathrm{~s}^{-1}$. In the necking, the volume fraction of martensite measured is $V_{\alpha^{\prime}} \approx 35 \%$. This considerable amount of martensite formed under dynamic loading proves that plastic deformation is the dominant mechanism which resides behind the transformation phenomenon in this material. The free energy supplied by the straining of the sample relegates to a secondary role the increase of temperature taking place during the course of plastic deformation.

\section{Acknowledgements}

The researcher of the University Carlos III of Madrid is indebted to the Ministerio de Ciencia e Innovacion de España (Project DPI/2008-06408) and to the Comunidad Autónoma de Madrid (Project CCG08-UC3M/MAT-4464) for the financial support received which allowed for conducting part of this work. 
The authors express their thanks to Mr. Philippe and Mr. Tobisch from the company Zwick for the facilities conferred to perform the tensile tests at high strain rates.

The authors express their thanks to Mr. Wary for his technical support.

\section{References}

[1] T. Angel, J. Iron Steel Inst. 177 (1954) 165-174.

[2] G.B. Olson, M. Cohen, Metall. Trans. A 6 (1975) 791-795

[3] S. Curtze, V.T. Kuokkala, M. Hokka, P. Peura, Mater. Sci. Eng. A 507 (2009) 124-131.

[4] L. Delannay, P. Jacques, T. Pardoen, Int. J. Solids Struct. 45 (2008) 1825-1843.

[5] F.D. Fischer, G. Reisner, E. Werner, K. Tanaka, G. Cailletaud, T. Antretter, Int. J. Plasticity 16 (2000) 723-748.

[6] C.L. Magee, Transformation kinetics, micro-plasticity and aging of martensite in Fe-31Ni, Ph.D. Thesis, Carnegie Institute of Technology, Pittsburgh, PA, 1966.

[7] G.W. Greenwood, R.H. Johnson, Proc. R. Soc. 403A (1965) 283.

[8] J.B. Leblond, J. Devaux, J.C. Devaux, Int. J. Plasticity 5 (1989) 551-573.

[9] S.S. Hecker, M.G. Stout, K.P. Staudhammer, J.L. Smith, Metall. Trans. A 13A (1982) 619-626

[10] Y. Tomita, T. Iwamoto, Int. J. Mech. Sci. 37 (1995) 1295-1305.

[11] T. Iwamoto, T. Tsuta, Y. Tomita, Int. J. Mech. Sci. 40 (1998) 173-182.

[12] Y. Tomita, T. Iwamoto, Int. J. Mech. Sci. 43 (2001) 2017-2034.

[13] P. Rozenak, R. Bergman, Mater. Sci. Eng. A 437 (2006) 366-378.

[14] A.K. De, J.G. Speer, D.K. Matlock, D.C. Murdock, M.C. Mataya, R.J. Comstock, Metall. Mater. Trans. A 37 (2006) 1875-1886.

[15] V. Mertinger, E. Nagy, F. Tranta, J. Sólyom, Mater. Sci. Eng. A 481-482 (2008) $718-722$.
[16] J.A. Rodríguez-Martínez, R. Pesci, A. Rusinek, A. Arias, R. Zaera, D.A. Pedroche Int. J. Solids Struct. 47 (2010) 1268-1284.

[17] V. Hauk, Structural and Residual Stress Analysis by Nondestructive Methods, Elsevier, Amsterdam, 1997.

[18] K. Inal, R. Pesci, J.L. Lebrun, O. Diard, R. Masson, Fatigue Fract. Eng. Mater. Struct. 29 (2006) 685-696.

[19] J.A. Rodríguez-Martínez, A. Rusinek, P. Chevrier, R. Bernier, A. Arias, Int. J. Impact Eng. 37 (2010) 828-841.

[20] R. Guzmán, Y.E. Essa, J. Meléndez, J. Aranda, F. López, J.L. Pérez-Castellanos, Strain 45 (2009) 179-189.

[21] R. Guzmán, J. Meléndez, J. Zahr, J.L. Pérez-Castellanos, Exp. Mech. 50 (2010) 389-397.

[22] R. Pesci, K. Inal, S. Berveiller, E. Patoor, J.S. Lecomte, A. Eberhardt, Mater. Sci. Forum 524-525 (2006) 109-114.

[23] J.A. Rodríguez-Martínez, Advanced constitutive relations for modeling thermoviscoplastic behaviour of metallic alloys subjected to impact loading, Ph.D. Thesis, University Carlos III of Madrid-University Paul Verlaine of Metz/ENIM 2010.

[24] A. Rusinek, R. Zaera, J.R. Klepaczko, R. Cheriguene, Acta Mater. 53 (2005) 5387-5400.

[25] P. Hedström, U. Lienert, J. Almer, M. Odén, Scripta Mater. 56 (2007) 213-216.

[26] P. Haušild, V. Davydov, J. Drahocoupil, M. Landa, P. Pilvin, Mater. Des. 31 (2010) 1821-1827.

[27] S. Allain, P. Cugy, C. Scott, J.P. Chateau, A. Rusinek, A. Deschamp, Int. J. Mater. Res. 99 (2008) 734-738.

[28] A. Rusinek, W.K. Nowacki, S.P. Gadaj, J.R. Klepaczko, J. Phys. IV 110 (2003) 411-416.

[29] D. Macdougall, Exp. Mech. 40 (2000) 298-306.

[30] A. Rusinek, J.R. Klepaczko, Mater. Des. 30 (2009) 35-48.

[31] J.A. Rodríguez-Martínez, A. Rusinek, R. Pesci, Thin-Walled Struct. 48 (2010) 966-978. 